\title{
Single-incision laparoscopic cholecystectomy versus conventional four-port laparoscopic cholecystectomy: a systematic review and meta-analysis
}

\author{
Laura Evers $^{1} \cdot$ Nicole Bouvy $^{2} \cdot$ Dion Branje $^{1} \cdot$ Andrea Peeters $^{3}$
}

Received: 17 September 2016/Accepted: 27 November 2016/Published online: 30 December 2016

(c) The Author(s) 2016. This article is published with open access at Springerlink.com

\begin{abstract}
Background Single-incision laparoscopic cholecystectomy (SILC) might maximize the advantages of laparoscopic cholecystectomy (LC) by reducing postoperative pain and improving cosmesis. However, the safety and feasibility of SILC has not yet been established. This study assesses safety, patient reported outcome measures and feasibility of SILC versus conventional LC.

Methods Literature search for RCT's comparing SILC with conventional LC in gallstone-related disease was performed in PubMed and Embase. The conventional LC was defined as two $10-\mathrm{mm}$ and two $5-\mathrm{mm}$ ports. Study selection was done according to predefined criteria. Two reviewers assessed the risk of bias. Pooled outcomes were calculated for adverse events, pain, cosmesis, quality of life and feasibility using fixed-effect and random-effects models.

Results Nine RCT's were included with total of 860 patients. No mortality was observed. More mild adverse events (RR 1.55; 95\% CI 0.99-2.42) and significantly more serious adverse events (RR 3.00; 95\% CI 1.05-8.58) occurred in the SILC group. Postoperative pain (MD -0.46; 95\% CI -0.74 to -0.18 ) and cosmesis (SMD 2.38; 95\% CI $1.50-3.26)$ showed significantly better results for the SILC
\end{abstract}

Laura Evers

n.bouvy@mumc.nl

1 Maastricht University Medical Centre, Maastricht University, P.Debyelaan 25, PO Box 5800, 6202 AZ Maastricht, The Netherlands

2 Department of Surgery, Maastricht University Medical Centre, Maastricht, The Netherlands

3 Department of Clinical Epidemiology and Medical Technology Assessment, Maastricht University Medical Centre, Maastricht, The Netherlands group, but no differences were observed in quality of life. Operating time (MD 23.12; 95\% CI 11.59-34.65) and the need for additional ports (RR 11.43; 95\% CI 3.48-37.50) were significantly higher in the SILC group. No difference was observed in conversion to open cholecystectomy or hospital stay longer than $24 \mathrm{~h}$.

Conclusions SILC does not provide any clear advantages over conventional LC except for less postoperative pain and improved cosmesis. It is questionable whether these advantages outweigh the higher occurrence of adverse events and shortcomings in feasibility. Considering considerable heterogeneity and low methodological quality of the studies it is advisable to perform well-designed RCT's in the future to address the safety and clinical benefits of SILC.

Keywords Laparoscopic cholecystectomy · Singleincision · Conventional $\cdot$ Safety $\cdot$ Feasibility

Cholecystectomy has emerged as the standard surgical treatment for gallstone-related disease [1]. Since laparoscopic cholecystectomy (LC) is associated with reduced post-operative pain, a shorter hospital stay and a quicker convalescence compared to open cholecystectomy, it is accepted as the gold-standard surgical procedure [2]. In conventional LC, a multiport approach is applied, three or four ports are being used, usually four. Traditionally, two ports of $10 \mathrm{~mm}$ in size ensure the access of a camera and a clip applier. Manipulation of the gall bladder for adequate exposure of the field of surgery is accomplished with two ports of $5 \mathrm{~mm}$ in size [3]. Nowadays, an increasing number of groups use also different sizes of ports, for instance three 5-mm ports and one 10-mm port, using 5-mm clip appliers. Considering the benefits of LC over open laparoscopy, 
surgeons have attempted to use even less invasive surgical techniques by minimizing the number of incisions or using even smaller ports [4]. Single-incision laparoscopic cholecystectomy (SILC) might be a promising technique by reducing post-operative pain and improving cosmetic result due to the use of one port only [5]. However, there are concerns with regard to safety and feasibility. The SILC technique might impair visualization due to a lack of triangulation, and there is an increased chance of clashing of the instruments [5]. Moreover, fewer instruments can be used within the body at any given time [3,5]. Therefore, there might be tissue injury to the bile duct or other important structures such as blood vessels supplying the liver [3,5].

Meta-analyses have already compared SILC with LC, but the evidence in these articles is limited. In some of these articles, the control group did not correspond to traditional four-port LC, but included three-port or miniport LC [4, 6-8]. In this way, the comparison of SILC with LC might be biased due to different techniques used in LC. Moreover, some authors included observational studies because of a lack of published randomized controlled trials (RCTs) on this topic at time of publication, thereby limiting the quality of the evidence [7,9]. Only one well-conducted meta-analysis by Gurusamy et al. [3] has compared the results of SILC with a proper conventional LC control group. Based on the analysis of nine RCTs, the authors concluded that there was insufficient quality of evidence to determine any clear advantages. In addition, the safety of SILC had yet to be established. However, the SILC procedure has improved and newer devices have been developed, so this review included fairly outdated RCTs. Moreover, they included not only results of SILC, in two RCTs three-port laparoscopy was used as an experimental intervention, which complicates the interpretation of the results. For a sound comparison between SILC and LC, well-designed RCTs with the use of identical/comparable surgical techniques in each trial arm are indispensable. Therefore, the aim of this review is to compare the SILC procedure with a proper traditional four-port LC control group, including recent RCTs.

\section{Methods}

A systematic review with meta-analysis has been conducted to assess safety, patient-reported outcome measures and feasibility of SILC versus conventional LC in patients undergoing cholecystectomy for gallstone-related disease. Conventional four-port LC is defined as two 10-mm and two 5-mm ports. The review was conducted in accordance with the PRISMA Statement for reporting systematic reviews and meta-analyses [10].

\section{Literature search}

Two authors (LE and AP) independently performed a literature search of the databases PubMed and EMBASE. The keywords used were: "Laparoscopic Cholecystectomy", in combination with "LESS" or "transumbilical" or "SILC" or "SLC" or "single site" or "single incision" or "single acces(s)" or "single port" AND "Laparoscopic Cholecystectomy", in combination with "LC" or "MLC" or "four port" or "multi port" or "standard" or "conventional". The search was limited to papers published in English from 1 January 2011 until 24 March 2016.

\section{Study selection}

Two authors (LE and AP) independently reviewed all the titles and abstracts and reached a consensus with referral to a third author (NB) about which papers met the eligibility criteria. Consequently, the full-text papers were retrieved. After checking the papers and crosschecking their reference lists as well, the final selection of studies has been made. Articles were excluded if the control group consisted of three-port or miniport LC, even though the authors stated that conventional LC was performed. Studies that used three $5-\mathrm{mm}$ ports and one $10-\mathrm{mm}$ port were also excluded. Other reason for exclusion was an unclear definition of the control group.

\section{Data extraction and validity assessment}

Two reviewers (LE and DB) extracted the data and assessed the risk of bias. In case of discrepancy, a third reviewer has been approached (AP).

The following information was extracted from each included study: (1) basic study characteristics, (2) patient characteristics, (3) safety, incl. mortality and adverse events, (4) patient-reported outcome measures such as pain score measured post-operative and at days 1,2 and 7, cosmesis, and quality of life measured 1, 3, 6 and 12 months after surgery, (5) feasibility, incl. conversion to open cholecystectomy, additional ports needed, operating time and hospital stay.

The risk of bias was assessed by using the Cochrane Collaboration's tool for assessing risk of bias as stated in "The Cochrane handbook for systematic reviews of intervention" [11] and the Cochrane Hepato-Biliary Group module [12]. The following domains were assessed: (1) random sequence generation; (2) allocation concealment; (3) blinding of participants and personnel; (4) blinding of outcome assessment; (5) incomplete outcome data; (6) selective outcome reporting; (7) for-profit bias. A judgement of "low risk" of bias, "high risk" of bias or "unclear risk" was assigned and elucidated with a comment or quote. 


\section{Data analysis}

\section{Summary measures}

For binary outcomes such as mortality, adverse events, conversion to open cholecystectomy and the need of additional ports, a risk ratio (RR) with $95 \%$ confidence interval (CI) was computed. For continuous outcomes such as the VAS score, operating time and hospital stay, the mean difference (MD) with 95\% CI was calculated. For outcomes in which different scales are used such as quality of life and cosmesis, the standardized mean difference (SMD) with 95\% CI was calculated.
Synthesis of results

The meta-analysis was conducted by using the computer program RevMan 5.3 [13]. The statistical method for binary outcomes was the Mantel-Haenszel method, given the few events. The statistical method for continuous outcomes was the inverse variance method. Heterogeneity was explored with the $\chi^{2}$ test with significance set at a $p$ value of 0.10 , and the quantity of inconsistency was measured by the $I^{2}$ statistic. The following thresholds for interpretation of $I^{2}$ were maintained: 30-60\%-moderate heterogeneity; 50-90\%—-substantial heterogeneity; 75-100\%—considerable heterogeneity.

Fig. 1 Study flow diagram

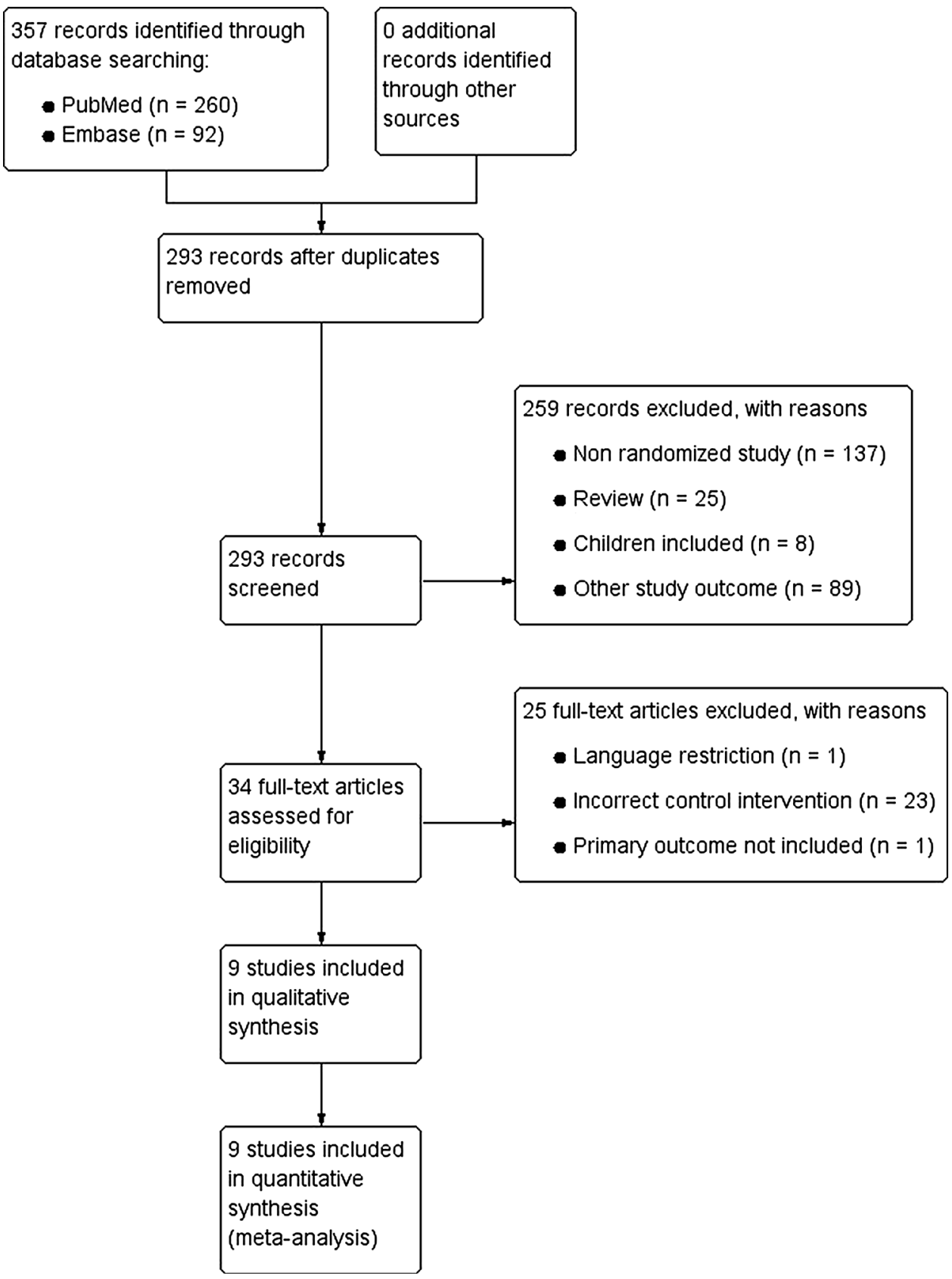


A fixed-effect model or a random-effects model was used for pooling depending on the found heterogeneity. The models used for the analysis and the results in the form of a Forrest plot are presented in the paper in "Results" section. In few instances, the SD of the continuous outcome measures was not available. In these cases, a SD was calculated from the available mean and range according to the methods of Hozo et al. [14].

\section{Publication bias}

"The Cochrane handbook for systematic reviews of intervention-10.4.3.1 recommendations on testing for funnel plot asymmetry" [11] advises to explore publication bias with visual asymmetry on a funnel plot when 10 or more trials are identified. As only nine studies were included in this review, the power was too low to distinguish chance from real asymmetry so publication bias was not evaluated.

\section{Results}

\section{Baseline features}

A total of 357 records were identified by the search of PubMed $(n=260)$ and EMBASE $(n=92)$. Figure 1 shows the article selection. After manual removal of duplicates, 293 records were screened. Of these, 259 records were discarded based on title and abstract because these papers investigated other study outcomes $(n=89)$, were non-randomized studies $(n=137)$, included children $(n=8)$ or were reviews $(n=25)$. For the remaining 34 records, full-text articles were retrieved and examined in detail for eligibility. Twenty-five additional studies were discarded, because one study could not be feasibly translated into English or Dutch, one study did not include our primary outcome measures, and twenty-three studies used an incorrect control group.

A total of nine RCTs published in English met the eligibility criteria and were included in the systematic review and meta-analysis [15-23]. The follow-up period of these studies ranged from 1 to 16 months, and the number of included patients ranged from 34 to 250 . A total of 860 participants were randomized to SILC $(n=430)$ or conventional LC ( $n=430)$. Main inclusion criteria comprised adults (18 years or older) with an ASA grade between I and III, scheduled for elective cholecystectomy. Main exclusion criteria were pregnancy or lactation, coagulopathic patients, acute cholecystitis or previous upper abdominal surgery. Countries of origin were Switzerland, Turkey, Denmark, Egypt, Brazil, Germany and Italy. There were six unicentre and three multicentre studies. All studies compared SILC with conventional LC. Successful completion of SILC ranged between 72 and 100\%. Detailed information on the characteristics of included studies is presented in Table 1.

\section{Quality assessment of the included studies}

The risk of bias per domain and in individual studies is summarized in Figs. 2 and 3. A considerable heterogeneity between studies was observed. Overall, multiple studies were at "high risk" or "unclear risk" of bias. The only studies with "low risk" of bias were the studies conducted by Abd Ellatif et al. [15] and Saad et al. [21].

Table 1 Basic study and patient characteristics

\begin{tabular}{|c|c|c|c|c|c|c|c|c|c|c|c|}
\hline \multirow[t]{2}{*}{ Reference } & \multicolumn{2}{|c|}{$\begin{array}{l}\text { Sample } \\
\text { size }\end{array}$} & \multicolumn{2}{|c|}{$\begin{array}{l}\text { Age, mean, } \\
\text { years }\end{array}$} & \multicolumn{2}{|c|}{$\begin{array}{l}\text { Sex male/ } \\
\text { female }\end{array}$} & \multicolumn{2}{|c|}{ BMI $\left(\mathrm{kg} / \mathrm{m}^{2}\right)$} & \multicolumn{2}{|c|}{ ASA grade (I:II:III) } & \multirow[t]{2}{*}{$\begin{array}{l}\text { Successful completion SILC procedure } \\
(\%)\end{array}$} \\
\hline & SILC & $\mathrm{LC}$ & SILC & $\mathrm{LC}$ & SILC & $\mathrm{LC}$ & SILC & $\mathrm{LC}$ & SILC & $\mathrm{LC}$ & \\
\hline Lurje [20] & 48 & 48 & 48 & 44 & $15: 33$ & $19: 29$ & 25 & 26 & $37: 10: 1$ & $31: 17: 0$ & 90 \\
\hline Sulu [23] & 30 & 30 & 48 & 44 & $9: 21$ & $12: 18$ & 30.3 & 28.54 & $12: 15: 3$ & $16: 14: 0$ & NA \\
\hline Jørgensen [17] & 60 & 60 & 46 & 46 & $0: 60$ & $0: 60$ & 26.6 & 24 & $43: 16: 1$ & $36: 24: 0$ & 72 \\
\hline Abd Ellatif [15] & 125 & 125 & 48 & 47 & $30: 95$ & $37: 88$ & 26.9 & 29.5 & $75: 35: 15$ & $71: 34: 20$ & 97 \\
\hline Luna [19] & 20 & 20 & NA & NA & NA & NA & NA & NA & NA & NA & 90 \\
\hline Saad [21] & 35 & 35 & 45 & 49 & $28: 7$ & $26: 9$ & 25.4 & 25.4 & 14:20:1 & $13: 21: 1$ & 97 \\
\hline Sinan [22] & 17 & 17 & 48 & 48 & $4: 13$ & $8: 9$ & 27.3 & 27.2 & NA & NA & 100 \\
\hline Bucher [16] & 75 & 75 & 42 & 44 & NA & NA & 26 & 25 & NA & NA & 97 \\
\hline Lirici [18] & 20 & 20 & 45 & 50 & $6: 14$ & $6: 14$ & 25 & 27 & 5:14:1 & $4: 12: 4$ & 90 \\
\hline
\end{tabular}

ASA grade American Society of Anaesthesiologists grade; BMI body mass index; LC laparoscopic cholecystectomy; NA not available; SILC single-incision laparoscopic cholecystectomy

* Age and sex ratio are presented as SILC/LC 
Fig. 2 Risk of bias summary

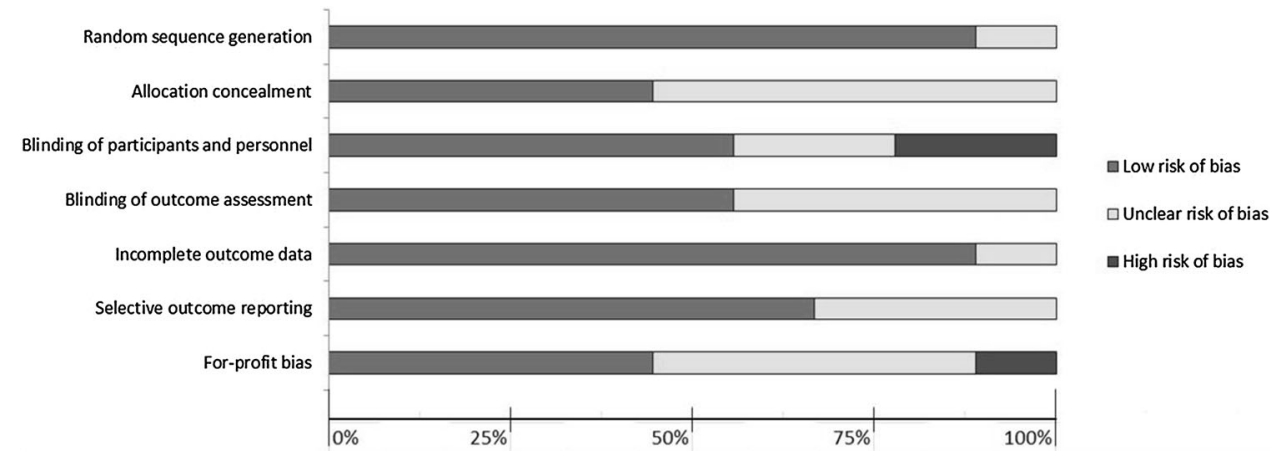

Fig. 3 Risk of bias in individual studies

\begin{tabular}{|c|c|c|c|c|c|c|c|}
\hline & 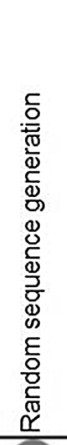 & 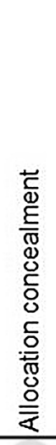 & 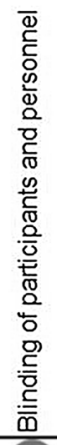 & 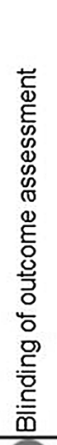 & 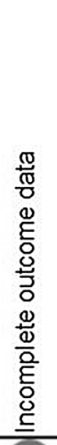 & 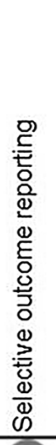 & 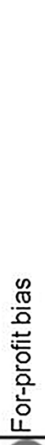 \\
\hline Lurje (2015) & + & $?$ & + & + & + & + & + \\
\hline Sulu (2015) & + & $?$ & - & $?$ & + & $?$ & $?$ \\
\hline Jørgensen (2014) & + & + & + & $?$ & $?$ & + & + \\
\hline Abd Ellatif (2013) & + & + & + & + & + & + & + \\
\hline Luna (2013) & $?$ & $?$ & $?$ & $?$ & + & $?$ & - \\
\hline Saad (2013) & + & + & + & + & + & + & + \\
\hline Sinan (2012) & + & $?$ & $?$ & + & + & $?$ & $?$ \\
\hline Bucher (2011) & + & $?$ & - & $?$ & + & + & $?$ \\
\hline Lirici (2011) & + & + & + & + & + & + & $?$ \\
\hline
\end{tabular}

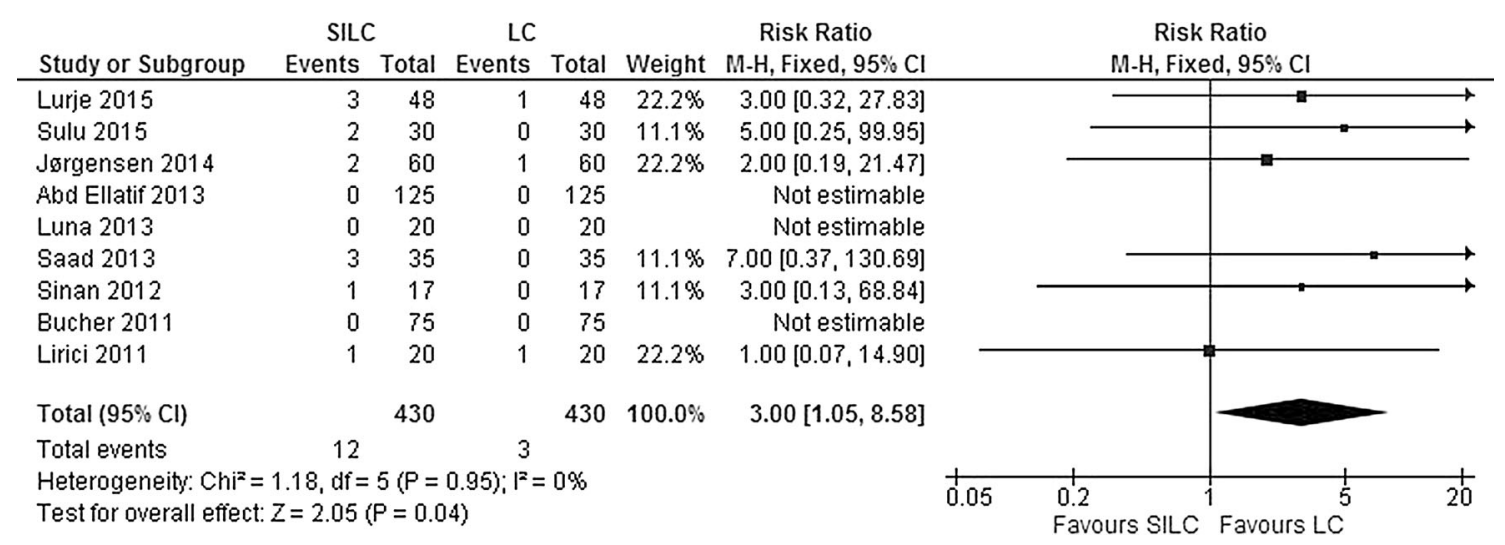

Fig. 4 Forrest plot of serious adverse events for single-incision laparoscopic cholecystectomy (SILC) versus conventional laparoscopic cholecystectomy (LC). A Mantel-Haenszel fixed-effect model was used to calculate risk ratios with $95 \%$ confidence intervals 


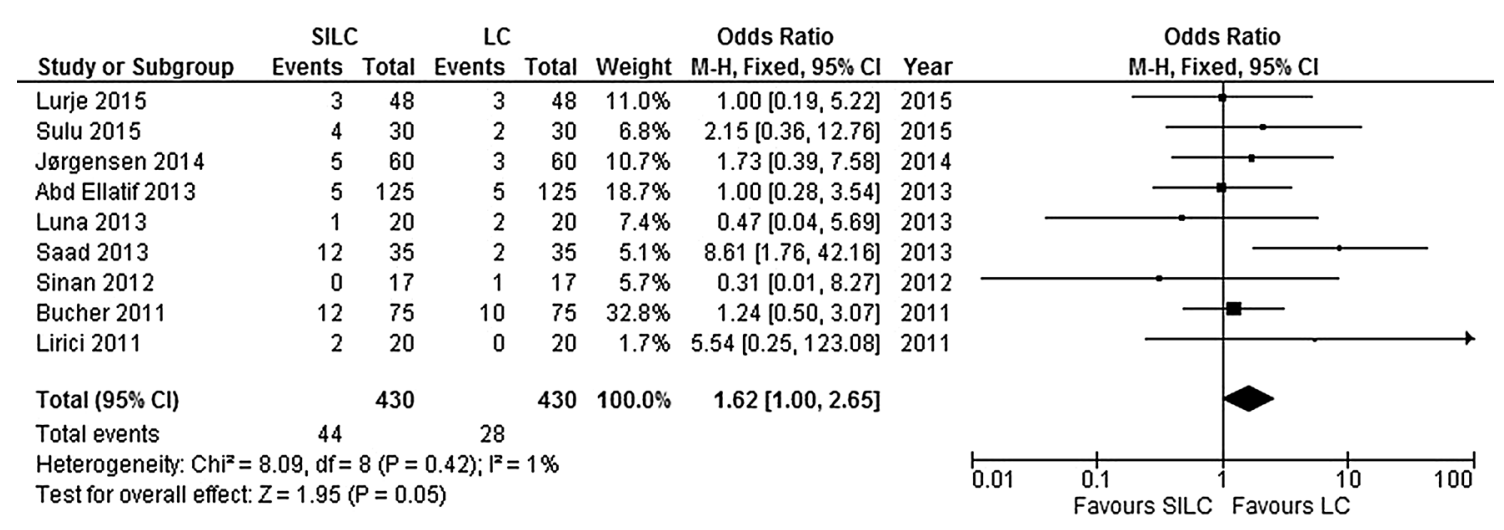

Fig. 5 Forrest plot of mild adverse events for single-incision laparoscopic cholecystectomy (SILC) versus conventional laparoscopic cholecystectomy (LC). A Mantel-Haenszel fixed-effect model was used to calculate risk ratios with $95 \%$ confidence intervals

Table 2 Bile duct/vessel injury and port-site hernia after SILC and LC

\begin{tabular}{|c|c|c|c|c|c|c|c|}
\hline \multirow[t]{2}{*}{$\begin{array}{l}\text { Reference } \\
\text { Year }\end{array}$} & \multirow[t]{2}{*}{$\begin{array}{l}\text { Sample } \\
\text { size }\end{array}$} & \multicolumn{2}{|c|}{$\begin{array}{l}\text { Biliary } \\
\text { duct/vessel } \\
\text { injury }\end{array}$} & \multicolumn{2}{|c|}{$\begin{array}{l}\text { Port-site } \\
\text { hernia }\end{array}$} & \multirow[t]{2}{*}{$\begin{array}{l}\text { Follow-up } \\
\text { (months) }\end{array}$} & \multirow[t]{2}{*}{ Method of SILC } \\
\hline & & SILC & $\mathrm{LC}$ & SILC & $\mathrm{LC}$ & & \\
\hline $\begin{array}{l}\text { Lurje [20] } \\
2015\end{array}$ & 98 & 0 & 0 & 2 & 0 & 12 & $\begin{array}{l}\text { Transumbilical incision of } 20-25 \mathrm{~mm} \text { for SILS }{ }^{\mathrm{TM}} \text { PT12 Port (Covidien Inc., } \\
\text { Norwalk, California, USA) with } 4 \text { openings }\end{array}$ \\
\hline $\begin{array}{l}\text { Sulu } \\
\text { [23] } 2015\end{array}$ & 60 & NA & NA & 2 & 0 & 18 & Transumbilical incision for SILS ${ }^{\circledR}$ port (Covidien, Mansfield MA) \\
\hline $\begin{array}{l}\text { Jørgensen } \\
{[17] 2014}\end{array}$ & 120 & 1 & 0 & 1 & 1 & 12 & $\begin{array}{l}\text { Transumbilical incision of } 25-30 \mathrm{~mm} \text { for SILS port }{ }^{\circledR} \text { (Covidien, Mansfield, } \\
\text { Massachusetts, USA) with } 3 \text { openings }\end{array}$ \\
\hline $\begin{array}{r}\text { Abd Ellatif } \\
{[15] 2013}\end{array}$ & 250 & 0 & 0 & 0 & 0 & 6 & Two transumbilical ports, one of $10 \mathrm{~mm}$ and one of $5 \mathrm{~mm}$ \\
\hline $\begin{array}{l}\text { Luna }[19] \\
2013\end{array}$ & 40 & 0 & 0 & 0 & 0 & 1 & $\begin{array}{l}\text { Transumbilical incision for the SITRACC }{ }^{\circledR} \text { device (EDLO, Rio Grande do } \\
\text { Sul, Brazil) with one } 10 \text {-mm and three } 5 \text {-mm ports }\end{array}$ \\
\hline $\begin{array}{l}\text { Saad }[21] \\
2013\end{array}$ & 70 & 0 & 0 & 1 & 0 & 12 & $\begin{array}{l}\text { Intra-umbilical 20-mm incision for SILS port }{ }^{\circledR} \text { (Covidien, Norwalk, } \\
\text { Connecticut, USA) with } 3 \text { openings }\end{array}$ \\
\hline $\begin{array}{l}\text { Sinan } \\
\text { [22] } 2012\end{array}$ & 34 & 0 & 0 & 1 & 0 & 6 & $\begin{array}{l}\text { Intra-umbilical } 25-\mathrm{mm} \text { incision for SILS port }{ }^{\circledR} \text { (Covidien, Norwalk, } \\
\text { Connecticut, USA) with } 3 \text { openings }\end{array}$ \\
\hline $\begin{array}{l}\text { Bucher }[16] \\
2011\end{array}$ & 150 & 0 & 0 & 0 & 0 & 1 & $\begin{array}{l}\text { Intra-umbilical 15-mm incision for TriPort }{ }^{\circledR} \text { (Advanced Surgical Concepts, } \\
\text { Wicklow, Ireland) with } 3 \text { openings }\end{array}$ \\
\hline $\begin{array}{l}\text { Lirici }[18] \\
2011\end{array}$ & 40 & 0 & 1 & NA & NA & 1 & $\begin{array}{l}\text { Intra-umbilical } 20-\mathrm{mm} \text { incision for } \text { TriPort }^{\circledR} \text { (Olympus America, Center } \\
\text { Valley, PA) with } 3 \text { openings }\end{array}$ \\
\hline
\end{tabular}

LC laparoscopic cholecystectomy; $N$ : NA: not available; SILC single-incision laparoscopic cholecystectomy

\section{Meta-analysis}

\section{Primary outcome measures}

Mortality and morbidity The data were available from all nine studies. No mortality was reported in either SILC or conventional LC. Serious adverse events included bile duct injury, re-operations, intra-abdominal collections or bile leaks requiring drainage or infected intra-abdominal collections. Mild adverse events include complications such as wound infections, bile leaks or abdominal collections that were easily treated or settled spontaneously. The pooled risk ratio shows a significant difference in the occurrence of serious adverse events, with more events occurring in the SILC group (RR 3.00; 95\% CI 1.05-8.58) (Fig. 4). There was no significant heterogeneity between studies for this outcome $\left(\chi^{2}=1.18, d f=5, I^{2}=0 \%\right)$. In addition, more mild adverse events occurred in the SILC group (RR 1.55; 95\% CI 0.99-2.42) (Fig. 5). There was no significant heterogeneity between studies $\left(\chi^{2}=7.25, \quad d f=8\right.$, $I^{2}=0 \%$ ). Table 2 presents an overview of bile duct/vessel injury and port-site hernia after SILC and LC. 


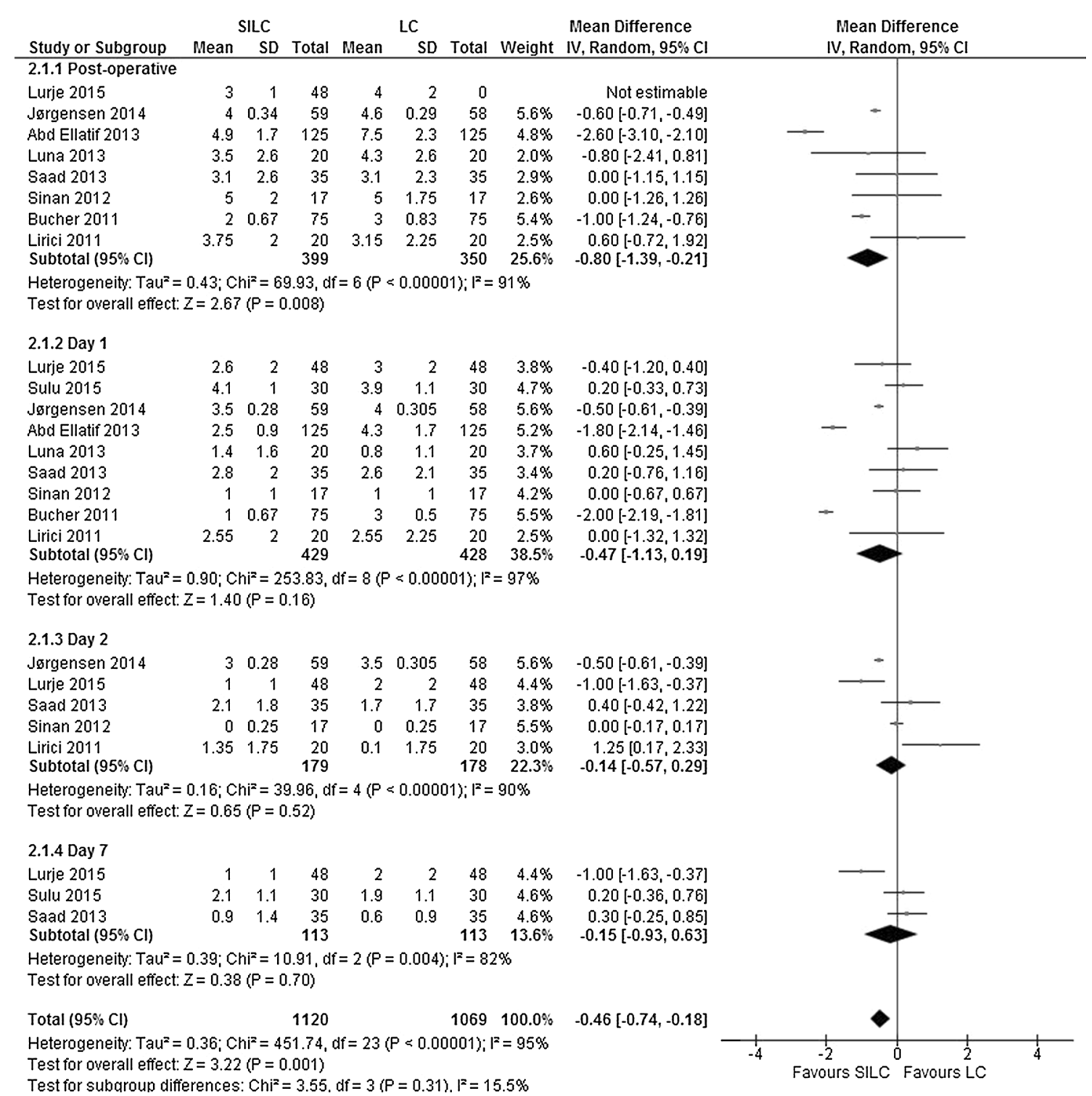

Fig. 6 Forrest plot of post-operative pain for single-incision laparoscopic cholecystectomy (SILC) versus conventional laparoscopic cholecystectomy (LC). An inverse variance random-effects model was used to calculate mean difference with $95 \%$ confidence intervals

\section{Secondary patient-reported outcome measures}

VAS pain score: All nine studies investigated post-operative pain with an 11-point VAS scale (ranging from 0 to 10 , with a high score indicating more pain) at different time points (postoperatively and at days 1, 2 and 7 after surgery). Overall, there was a significant lower pain score in favour of SILC (MD -0.46; 95\% CI -0.74 to -0.18 ). There was a considerable heterogeneity between the studies $\left(\chi^{2}=451.74, d f=23, I^{2}=95 \%\right)$. The calculated overall effect was due to a significant difference in pain postoperatively. At days 1, 2 and 7, no difference was found (Fig. 6).

Cosmesis: Six studies explored the cosmetic outcome at different time points (after 1, 3, 6 or 12 months). Cosmesis was assessed with scales using a high or low score for better cosmetic results. Scales with a high score meaning a better result included a VAS scale (ranging from 0 to 10) [15, 18] and a Cosmesis Score (ranging from 3 to 24) [20]. Scales with a low score meaning a better result included a Body Image Scale (ranging from 5 to 20) [16, 20], a Numerical Rating Scale (ranging from 0 to 10) [17] and a Cosmesis Score (ranging from 1 to 5) [21]. Cosmesis was significantly better in the SILC group at all time points, and the overall SMD was in favour of SILC (SMD 2.38; 95\% CI 1.50-3.26). The heterogeneity between studies was considerable $\left(\chi^{2}=544.68, d f=12, I^{2}=98 \%\right.$ ) (Fig. 7).

Quality of life: Five studies explored quality of life at different time points (after 1, 3, 6 or 12 months). The questionnaires used for quality of life assessment included 


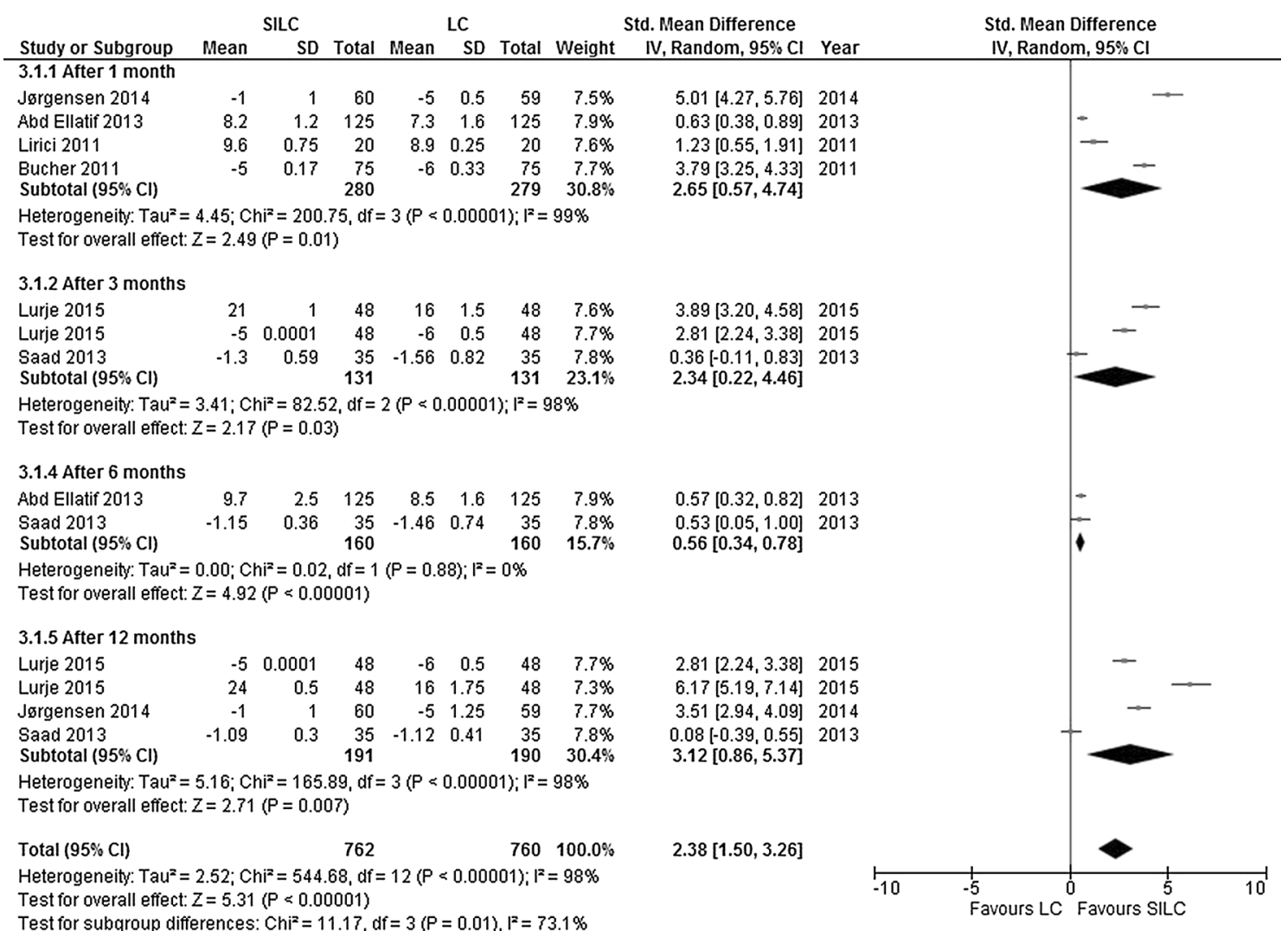

Fig. 7 Forrest plot of cosmesis for single-incision laparoscopic cholecystectomy (SILC) versus conventional laparoscopic cholecystectomy (LC). An inverse variance random-effects model was used to calculate standardized mean difference with $95 \%$ confidence intervals

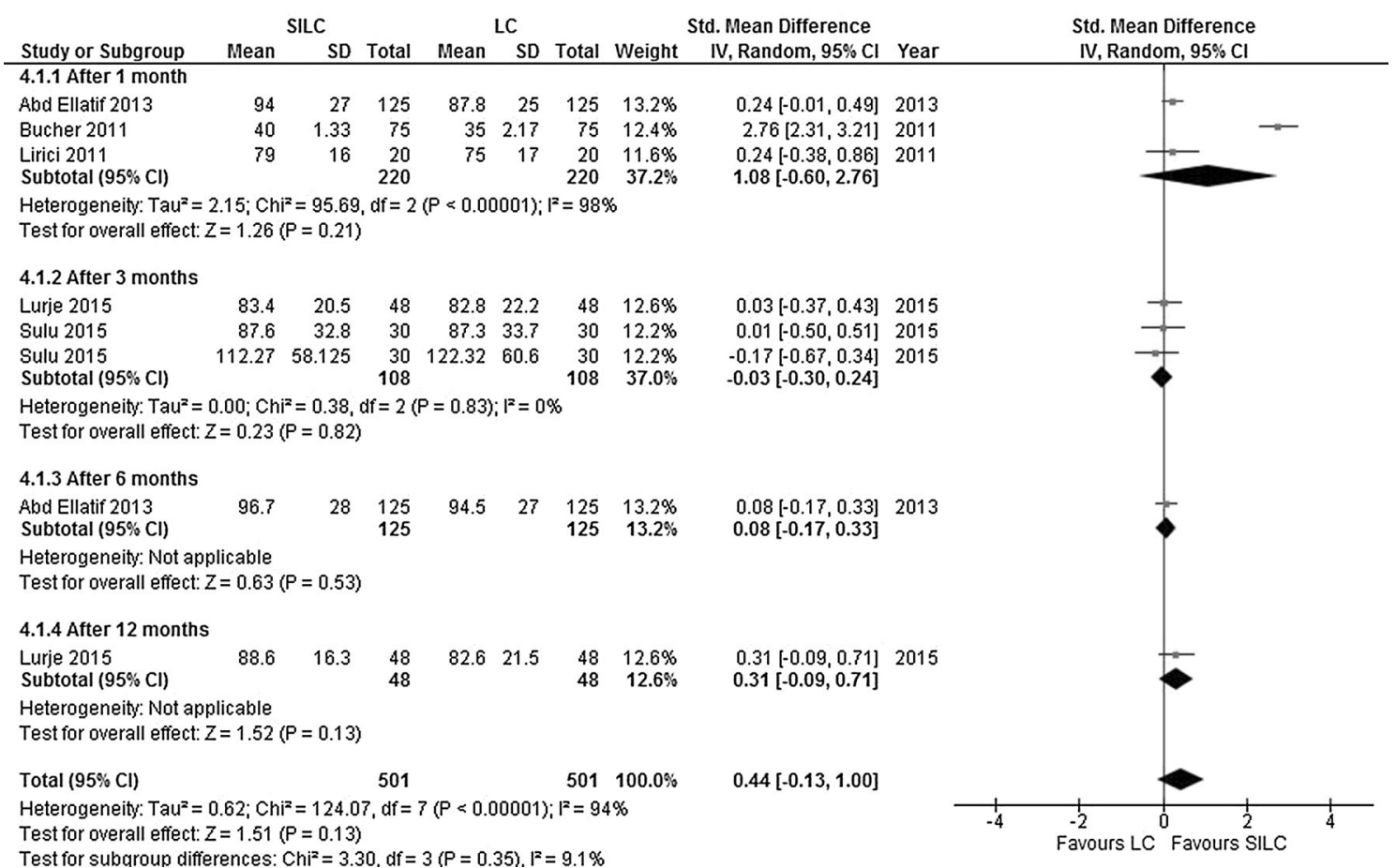

Fig. 8 Forrest plot of quality of life for single-incision laparoscopic cholecystectomy (SILC) versus conventional laparoscopic cholecystectomy (LC). An inverse variance random-effects model was used to calculate standardized mean difference with $95 \%$ confidence intervals 


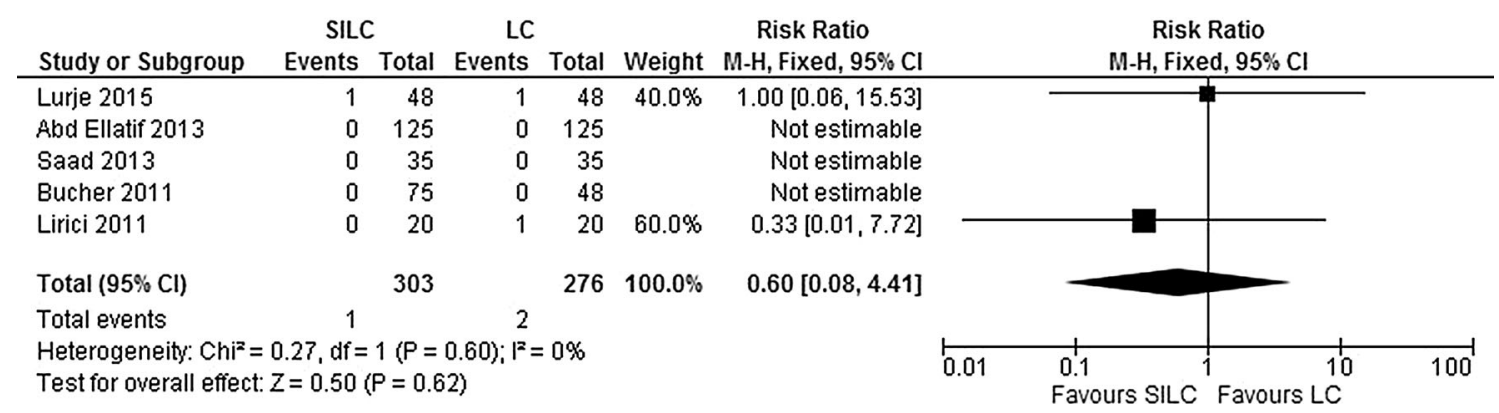

Fig. 9 Forrest plot of conversion to open cholecystectomy for single-incision laparoscopic cholecystectomy (SILC) versus conventional laparoscopic cholecystectomy (LC). A Mantel-Haenszel fixed-effect model was used to calculate risk ratios with $95 \%$ confidence intervals

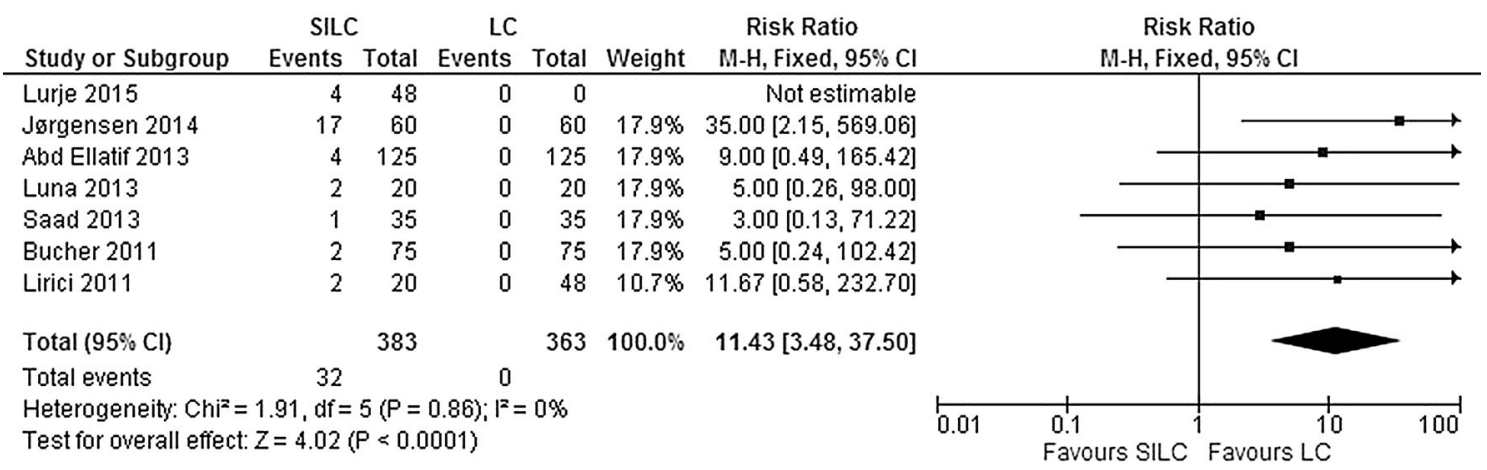

Fig. 10 Forrest plot of additional ports needed for single-incision laparoscopic cholecystectomy (SILC) versus conventional laparoscopic cholecystectomy (LC). A Mantel-Haenszel fixed-effect model was used to calculate risk ratios with 95\% confidence intervals

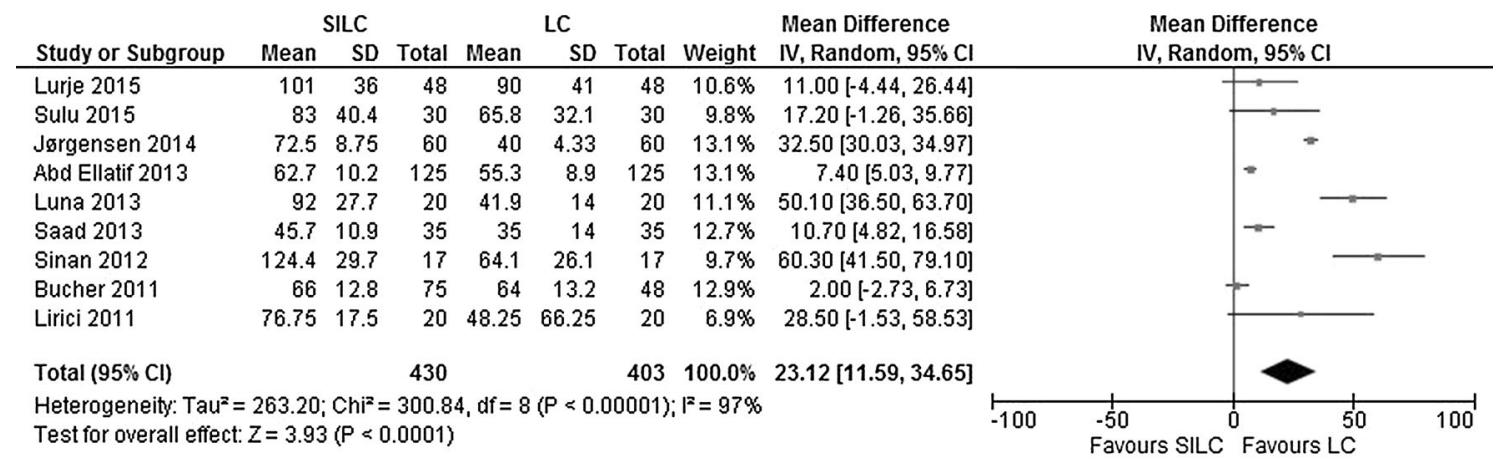

Fig. 11 Forrest plot of operating time in minutes for single-incision laparoscopic cholecystectomy (SILC) versus conventional laparoscopic cholecystectomy (LC). An inverse variance random-effects model was used to calculate mean difference with $95 \%$ confidence intervals

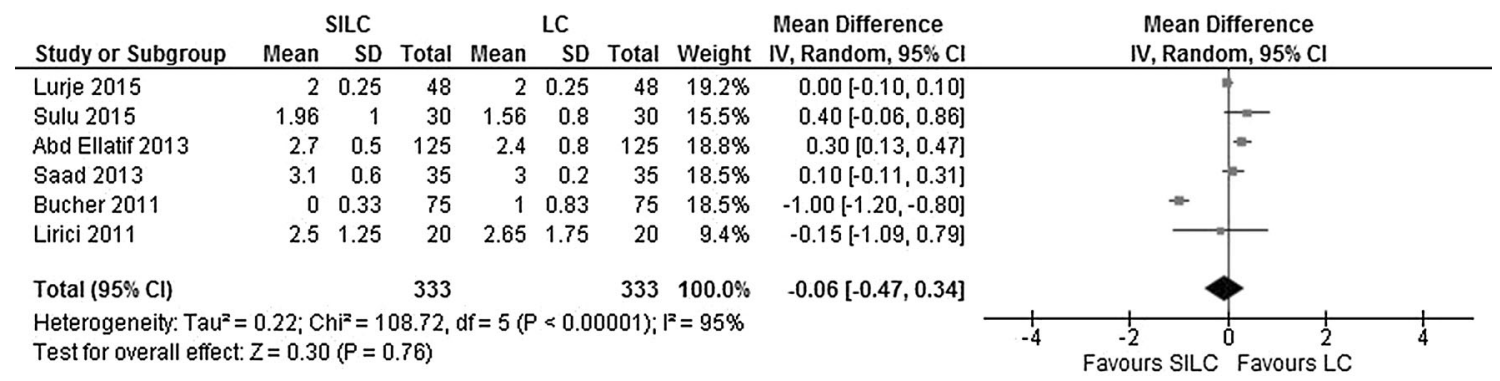

Fig. 12 Forrest plot of hospital stay longer than 1 day for single-incision laparoscopic cholecystectomy (SILC) versus conventional laparoscopic cholecystectomy (LC). An inverse variance random-effects model was used to calculate mean difference with $95 \%$ confidence intervals 
EQ-5D [15], GIQLI [23], SF-12 [16] and SF-36 $[18,20,23]$. There was no significant difference in quality of life (SMD $0.44 ; 95 \%$ CI -0.13 to 1.00 ). The heterogeneity between studies was high $\left(\chi^{2}=124.07, d f=7\right.$, $\left.I^{2}=94 \%\right)($ Fig. 8).

\section{Secondary procedure-related outcome measures}

Conversion to open cholecystectomy: Conversion to open cholecystectomy was addressed in five studies. There was no significant difference in the proportion of conversion between both groups (RR 0.62; 95\% CI 0.08-4.91). No significant heterogeneity between studies was found $\left(\chi^{2}=0.27, d f=1, I^{2}=0 \%\right)$ (Fig. 9).

Additional ports needed: Seven studies explored the need of additional ports in both groups during surgery. The need for additional ports was significantly higher in the SILC group (RR 11.43; 95\% CI 3.48-37.50). There was no significant heterogeneity between studies $\left(\chi^{2}=1.91\right.$, $d f=5, I^{2}=0 \%$ ) (Fig. 10).

Operating time: All nine studies reported the operating time. According to the calculated mean difference, there was a significant longer operating time in the SILC group (MD 23.12; 95\% CI 11.59-34.65). The heterogeneity between studies was considerable $\left(\chi^{2}=300.84, d f=8\right.$, $\left.I^{2}=97 \%\right)$ (Fig. 11).

Hospital stay: A hospital stay longer than $24 \mathrm{~h}$ was reported in six studies. There was no significant difference observed between the groups (MD -0.06 ; $95 \% \mathrm{CI}-0.47$ $0.34)$. The heterogeneity between studies was considerable $\left(\chi^{2}=108.72, d f=5, I^{2}=95 \%\right)$ (Fig. 12).

\section{Discussion}

This systematic review included and analysed nine RCTs with total of 860 patients in order to assess safety, patientreported outcome measures and feasibility of SILC versus conventional LC in patients undergoing elective cholecystectomy for gallstone-related disease.

The results show advantages of the SILC procedure above the LC procedure regarding post-operative pain and cosmesis. At the same time, more adverse events and shortcomings in feasibility occurred in the SILC group.

Less post-operative pain and improved cosmesis in favour of the SILC procedure did not have any impact on quality of life as no differences were observed for this outcome between the two groups. Post-operative pain was significantly lower, and the overall pain score was in favour of SILC. However, at days 1, 2 and 7, no difference was found, suggesting that the decrease in post-operative pain is mainly important in the very early post-operative period. Cosmesis was significantly better in the SILC group at all time points. There were no significant differences in the conversion to open cholecystectomy or hospital stay longer than $24 \mathrm{~h}$. Operating time and the need for additional ports were significantly higher in the SILC group. Also significantly more serious and more mild adverse events occurred in the SILC group, indicating that SILC might not be as safe as the conventional LC. No mortality was found in both groups. However, it should be noted that most RCTs included only patients with a low ASA grade who were scheduled for elective cholecystectomy, thereby reducing the risk of mortality.

These results indicate that SILC offers benefits in terms of decreased post-operative pain and improved cosmesis, but it does not seem to improve quality of life or decrease the length of hospital stay. In contrast, SILC appears to increase the risk of adverse events, is frequently in need of additional ports and prolongs the operation time.

The presented study results must be interpreted with caution. Overall, the evidence from these nine RCTs is not strong enough to provide reliable results because multiple studies were at high risk or uncertain risk of bias, and a considerable heterogeneity between studies was observed. The only studies with low risk of bias were the studies conducted by Abd Ellatif et al. [15] and Saad et al. [21]. Moreover, the sample size was low in most studies.

Another limitation is due to the fact that the definition of cosmesis and quality of life were different across the studies. In addition, the learning curve associated with the adoption to SILC could induce differences in the operation time and the need for additional ports, because the experience of surgeons differed across studies.

There are some serious methodological issues, which might compromise the validity of the outcomes. Blinding of patients and personnel was at high risk of bias in most studies; objective patient-reported outcome measures such as post-operative pain, cosmesis and quality of life are susceptible for performance bias. In addition, multiple studies performed SILC with a specific device made by a company. Since for-profit bias was poorly evaluated in these studies, reliability of the results can be questionable due to possible conflict of interest. Moreover, the follow-up period was relatively short in most studies. In order to adequately assess long-term safety and cosmesis, a followup period of at least 1 year is desirable.

It should be also noted that a very specific group of patients was studied. Most RCTs only included patients scheduled for elective cholecystectomy with a low ASA grade, thereby disregarding emergency cholecystectomy. Moreover, most studies excluded obese patients. Therefore, the results presented in this systematic review are only applicable in non-obese patients with low ASA grade scheduled for elective cholecystectomy. There was no consensus regarding the technique and the devices used for 
SILC. This might have introduced inconsistencies in the results of this review.

Due to a relatively short follow-up in the included studies, the problem of trocar-site hernia might be underestimated, as this might occur even years after the surgery. In SILC technique, the size of the incision is bigger than in multiport approach so one could expect more incisional hernias. This could have a negative impact on the cosmetic outcome after SILC. Also in obese patients, one could expect a higher risk of hernias. These patients were, however, not included in the studies.

Limitation regarding the design of this systematic review might be the inclusion of studies published in English only. Further, in this review conventional four-port $\mathrm{LC}$ is defined as two $10-\mathrm{mm}$ and two $5-\mathrm{mm}$ ports. Currently, surgeons also use three $5-\mathrm{mm}$ ports and one $10-\mathrm{mm}$ port or even three ports only, instead of four. Inclusion of studies using these techniques could alter some of the conclusions of this study.

In the literature, several reviews exist on SILC versus conventional LC in patients scheduled for cholecystectomy for gallstone-related disease, but only one review performed by Gurusamy et al. [3] used the same definition of conventional LC as was used in this study. The above-mentioned review suggested that there was no significant difference in the proportion of mortality, serious complications, quality of life, cosmesis and conversion to open cholecystectomy or length of hospital stay. In addition, the authors reported a significant longer operation duration [3]. Some of the other published reviews suggest that SILC is safe and effective $[4,6]$, while others do not see any advantages or empathize to be cautious with SILC [5, 8]. Results on post-operative pain were controversial $[4,6,8]$.

In conclusion, low-quality evidence indicates that safety of SILC is debatable and that this procedure does not provide any clear advantages over conventional LC, except for a decrease in post-operative pain and an improvement in cosmetic result. However, we could not establish the impact of these outcomes on the quality of life. Therefore, it seems questionable whether the mentioned advantages of the SILC procedure outweigh the disadvantages such as occurrence of adverse events, the prolonged operating time and the frequent need for additional ports.

Well-designed RCTs with high-quality evidence and a follow-up period longer than 1 year are necessary to establish the safety profile and clinical benefits of SILC. These studies should also broaden the applicability of SILC by including patients with obesity and cases requiring emergency cholecystectomy. Furthermore, cost-effectiveness should be addressed in an economic evaluation, since high-quality data on economic aspects are very sparse.

\section{Compliance with ethical standards}

Disclosures Laura Evers, Andrea Peeters, Dion Branje and Nicole Bouvy declare no conflict of interest.

Open Access This article is distributed under the terms of the Creative Commons Attribution 4.0 International License (http://creative commons.org/licenses/by/4.0/), which permits unrestricted use, distribution, and reproduction in any medium, provided you give appropriate credit to the original author(s) and the source, provide a link to the Creative Commons license, and indicate if changes were made.

\section{References}

1. National Institute of Health Consensus Development Conference Statement (1992) NIH releases consensus statement on gallstones, bile duct stones and laparoscopic cholecystectomy. Am Fam Physician. 46(5):1571-1574

2. Keus F, de Jong JA, Gooszen HG, van Laarhoven CJ (2006) Laparoscopic versus open cholecystectomy for patients with symptomatic cholecystolithiasis. Cochrane Database Syst Rev 4:CD006231

3. Gurusamy KS, Vaughan J, Rossi M, Davidson BR (2014) Fewerthan-four ports versus four ports for laparoscopic cholecystectomy. Cochrane Database Syst Rev 2:Cd007109

4. Markar SR, Karthikesalingam A, Thrumurthy S, Muirhead L, Kinross J, Paraskeva P (2012) Single-incision laparoscopic surgery (SILS) versus conventional multiport cholecystectomy: systematic review and meta-analysis. Surg Endosc 26(5): 1205-1213

5. Fransen S, Stassen L, Bouvy N (2012) Single incision laparoscopic cholecystectomy: a review on the complications. J Minim Access Surg 1:1-5

6. Garg P, Thakur JD, Garg M, Menon GR (2012) Single-incision laparoscopic cholecystectomy versus conventional laparoscopic cholecystectomy: a meta-analysis of randomized controlled trials. J Gastrointest Surg Off J Soc Surg Aliment Tract 8:1618-1628

7. Milas M, Devedija S, Trkulja V (2014) Single incision versus standard multiport laparoscopic cholecystectomy: up-dated systematic review and meta-analysis of randomized trials. Surgeon J R Coll Surg Edinb Irel 5:271-289

8. Trastulli S, Cirocchi R, Desiderio J, Guarino S, Santoro A, Parisi A et al (2013) Systematic review and meta-analysis of randomized clinical trials comparing single-incision versus conventional laparoscopic cholecystectomy. Br J Surg 100(2):191-208

9. Tamini N, Rota M, Bolzonaro E, Nespoli L, Nespoli A, Valsecchi MG et al (2014) Single-incision versus standard multiple-incision laparoscopic cholecystectomy: a meta-analysis of experimental and observational studies. Surg Innov 5:528-545

10. Liberati A, Altman DG, Tetzlaff J, Mulrow C, Gotzsche PC, Ioannidis JP et al (2009) The PRISMA statement for reporting systematic reviews and meta-analyses of studies that evaluate health care interventions: explanation and elaboration. J Clin Epidemiol 62(10):e1-e34

11. Higgins J, Green S (2011) Cochrane handbook for systematic reviews of interventions: version 5.1.0 [updated March 2011]: The Cochrane Collaboration. http://handbook.cochrane.org/

12. Gluud CND, Klingenberg SL, Alexakis N, Als-Nielsen B, Colli A et al (2013) Cochrane Hepato-Biliary Group. About the Cochrane collaboration (Cochrane Review Groups (CRGs)). Issue 5, Art. No.: LIVER

13. Review Manager (RevMan) (2014) Version 5.3 ed: Copenhagen: The Nordic Cochrane Centre, The Cochrane Collaboration 
14. Hozo SP, Djulbegovic B, Hozo I (2005) Estimating the mean and variance from the median, range, and the size of a sample. BMC Med Res Methodol 5:13

15. Abd Ellatif ME, Askar WA, Abbas AE, Noaman N, Negm A, ElMorsy G et al (2013) Quality-of-life measures after single-access versus conventional laparoscopic cholecystectomy: a prospective randomized study. Surg Endosc 6:1896-1906

16. Bucher P, Pugin F, Buchs NC, Ostermann S, Morel P (2011) Randomized clinical trial of laparoendoscopic single-site versus conventional laparoscopic cholecystectomy. Br J Surg 98(12): $1695-1702$

17. Jorgensen LN, Rosenberg J, Al-Tayar H, Assaadzadeh S, Helgstrand F, Bisgaard T (2014) Randomized clinical trial of singleversus multi-incision laparoscopic cholecystectomy. Br J Surg 101(4):347-355

18. Lirici MM, Califano AD, Angelini P, Corcione F (2011) Laparoendoscopic single site cholecystectomy versus standard laparoscopic cholecystectomy: results of a pilot randomized trial. Am J Surg 2(1):45-52

19. Luna RA, Nogueira DB, Varela PS, Rodrigues Neto Ede O, Norton MJ, Ribeiro Ldo C et al (2013) A prospective, randomized comparison of pain, inflammatory response, and short-term outcomes between single port and laparoscopic cholecystectomy. Surg Endosc 4:1254-1259

20. Lurje G, Raptis DA, Steinemann DC, Amygdalos I, Kambakamba P, Petrowsky $\mathrm{H}$ et al (2015) Cosmesis and body image in patients undergoing single-port versus conventional laparoscopic cholecystectomy: a multicenter double-blinded randomized controlled trial (SPOCC-trial). Ann Surg 2(5):728-734

21. Saad S, Strassel V, Sauerland S (2013) Randomized clinical trial of single-port, minilaparoscopic and conventional laparoscopic cholecystectomy. Br J Surg 100(3):339-349

22. Sinan H, Demirbas S, Ozer MT, Sucullu I, Akyol M (2012) Single-incision laparoscopic cholecystectomy versus laparoscopic cholecystectomy: a prospective randomized study. Surg Laparosc Endosc Percutaneous Tech 22(1):12-16

23. Sulu B, Yildiz BD, Ilingi ED, Gunerhan Y, Cakmur H, Anuk T et al (2015) Single port versus four port cholecystectomy-randomized trial on quality of life. Adv Clin Exp Med 24(3): 469-473 